Cancer stem cells (CSCs) represent a distinctive population of tumour cells that control tumour initiation, progression, and maintenance. Their influence is great enough to risk the statement that successful therapeutic strategy must target CSCs in order to eradicate the disease. Because cancer stem cells are highly resistant to chemo- and radiotherapy, new tools to fight against cancer have to be developed. Expression of antigens such as ALDH, CD44, EpCAM, or CD133, which distinguish CSCs from normal cells, together with CSC immunogenicity and relatively low toxicity of immunotherapies, makes immune targeting of CSCs a promising approach for cancer treatment. This review will present immunotherapeutic approaches using dendritic cells, T cells, pluripotent stem cells, and monoclonal antibodies to target and eliminate CSCs.

Key words: cancer stem cells, tumour immunotherapy, cancer, dendritic cells, adoptive cell transfer, monoclonal antibodies.

Contemp Oncol (Pozn) 2015; 19 (1A): A52-A59

DOI: $10.5114 /$ wo.2014.47129

\section{Immunotargeting of cancer stem cells}

\author{
Eliza P. Kwiatkowska-Borowczyk ${ }^{1,2}$, Agnieszka Gąbka-Buszek ${ }^{1}$, \\ Jakub Jankowski ${ }^{1}$, Andrzej Mackiewicz ${ }^{1,2}$
}

${ }^{1}$ Department of Cancer Immunology, University of Medical Sciences, Poznan, Poland ${ }^{2}$ Diagnostic and Immunology Department, Greater Poland Cancer Centre, Poznan, Poland

\section{Introduction}

The mechanisms that control tumour initiation, growth, and dissemination by the immune system are still not fully understood. It is generally accepted that the host defence mechanisms may lose control of the cancer. There is also increasing evidence that at least some tumours can be eradicated by modulation/stimulation of the immune system by so-called immunotherapy. Moreover, various treatment modalities of cancer patients such as chemotherapy, radiotherapy, or surgery are accompanied by immunological reactions that coexist with the treatment, and "immunological support" is necessary for therapy efficacy. Since the discovery of cancer stem cells (CSCS), which form the core and drive the tumour growth, intensive research is being carried out to understand their biology and determine the means of their eradication. Due to their properties, CSCs have been proven be the force behind tumour initiation, progression, and maintenance. Moreover, they have transpired to be highly resistant to chemo- and radiotherapy that depends on CSC modified division patterns [1]. Their influence is great enough to risk the statement that a successful therapeutic strategy must target CSCs in order to eradicate the disease.

Current cancer immunotherapy strategies are based on vaccines, adoptive transfer of tumour-specific T-cells, and monoclonal antibodies targeting tumour cells or immunoregulatory molecules (immune check-points). Although the majority of clinical trials employing immunotherapy to treat cancer have been phase I, during the last 25 years the number of cancer immunotherapies in phase III clinical trials has exceeded 500. However, the only immunotherapeutic anticancer drugs that have received FDA approval are several monoclonal antibodies and sipuleucel-T (Provenge), the dendritic cell-based therapy for prostate cancer. It was recently reported that in certain settings CSCs might be immunogenic. Thus, they bear the potential to stimulate specific immune responses that could target and eliminate tumour CSCs in cancer patients.

\section{Dendritic cell-based cancer vaccines}

Dendritic cells (DC) are the most potent and versatile of antigen presenting cells, initiating and maintaining immune responses. To induce anticancer immunity, DCs presenting cancer antigens to $T$ cells are required. Dendritic cells vaccines are pointed at boosting cancer-specific effector $T$ cells to eradicate tumour cells, and at stimulating immunological memory to control the recurrence of cancer [2]. Although a number of clinical trials have been conducted, since the Food and Drug Administration's (FDA) approval of Provenge for prostate cancer treatment in 2010 no new DC-based vaccines have been granted marketing authorisation. That means that there is still potential to be discovered, possibly by retargeting dendritic cells at CSC antigens. 
Research conducted since the discovery of CSC has revealed the potential of DC vaccination to target CSCs of several types of solid tumours in preclinical settings. In the GL261 mouse model of glioma, Pellegata et al. demonstrated that DCs pulsed with glioma CSCs antigens provided more efficient protection against GL261 tumours than DCs pulsed with adherent GL261 antigens [3]. Treatment with CSC-based vaccine induced higher lytic activity of splenocytes as well as robust tumour infiltration by $\mathrm{CD}^{+}$ and $C D 4^{+} T$ cells. Dendritic cells-cancer stem cells (DC-CSC) vaccine cured $80 \%$ of "regular" GL261 tumours and $60 \%$ of CSC-initiated gliomas, whereas vaccination with regular vaccine cured none of the CSC-initiated tumours. In the rat $9 \mathrm{~L}$ brain tumour model it was demonstrated that DC vaccination of with $9 \mathrm{~L}$ CSCs significantly prolonged survival of gliosarcoma-bearing mice compared to vaccination with $9 \mathrm{~L}$ cells [4]. The protective effect was correlated with higher interferon $\gamma\left(\right.$ IFN- $\gamma$ ) production by $C D 8^{+} T$ cells in rats treated with DC-9L CSCs vaccine.

It has been shown that stem cell-enriched populations can be isolated using aldehyde dehydrogenase (ALDH) as a marker [5, 6]. Using this technique Ning et al. purified CSCs from D5 murine melanoma and SCC7 squamous cell cancer and used it as a source of antigens to prime DCs [7]. The authors found that enriched CSCs were immunogenic and more effective than unsorted heterogeneous tumour cells in inducing immunity of the host to reject the challenge of tumour cells. In both melanoma and squamous cell cancer models, CSC-based vaccines led to significant inhibition of tumour growth. Cancer stem cells-vaccinated animals showed systemic humoral responses with high level of IgG, which recognised CSCs and were efficient in CSC lysis in the presence of a complement. Moreover, CTLS from CSC-vaccinated mice were capable of killing corresponding CSCS in vitro, which proves that CSCS can be destroyed by CSC vaccine-primed immune response.

Successful therapeutic strategy against sarcoma was described for the murine CMS-4 tumour model [8]. Dendritic cells loaded with the lysate of induced vascular progenitor (iVP) cells derived from induced pluripotent stem (iPS) cells protected $75 \%$ of CMS-4 fibrosarcoma-inoculated mice from the development of tumours for a seven-week period, and $50 \%$ of animals were still alive tumour-free six months after tumour implantation. The seven-week survival of the DC-CMS-4-immunised group was 50\%, but all mice developed tumours after that time and died. In addition to slower growth, tumours that developed in mice vaccinated with DCs loaded with iVP cells revealed a limited vascular bed. Treatment elicited antitumor immunity targeting vascular and tumour cells demonstrated by CD $8^{+}$ $T$ lymphocytes cytotoxicity against endothelial cells and CMS-4 sarcoma.

Very recently the first report of a therapy targeting CSCS in solid tumour has been published. Seven patients that underwent surgery and chemo-radiotherapy were treated with immune therapy targeting autologous glioma stem cell (GSC) antigens [9]. Vaccination with DCs transfected with CSC-mRNA induced an immune response in all patients with no adverse autoimmune events or other side effects. In vitro studies of patient-derived T-cells revealed proliferation in response to GSC-lysate, indicating successful mobilisation of the immune system. Compared to historical-matched controls, the vaccinated patients had significantly longer progression-free survival (median 694 days vs. 236 days, $p=0.0018$ ). Five of the treated patients developed tumour recurrence, but later than most recurrences in the matched control group, in which all patients experienced progression. Currently, two other clinical trials are gathering participants for phase I studies to test the safety and effects of dendritic cell vaccines loaded with a lysate derived from an allogeneic glioblastoma stem-like cell line [10] or purified peptides from the CD133 CSC antigen [11] in newly diagnosed and recurrent glioblastoma.

\section{Adoptive immunotherapy}

Adoptive transfer of $T$ cells bypasses the antigen presentation step of immune response by immediately delivering effector cells as a therapeutic agent. The leukocytes are isolated from the patient, manipulated in vitro, and transferred back to the affected individual. To broaden the efficacy, these $T$ cells can be genetically modified to express antigen receptors with desired specificity by introducing tumour-specific TCRs or chimeric antigen receptors (CARs) [reviewed in 12, 13]. Moreover, the more accurate targeting of antigens may be crucial for successful therapy, and T-cell targeting CSCs could significantly enhance eradication of tumours.

There are reports showing that CSCs can be successfully targeted in vitro with both allogeneic as well as autologous T cells. In 2007 HLA-A2-restricted, naturally presented, CD8 ${ }^{+}$T-cell-defined tumour peptide of the CSC marker ALDH1 was identified for head and neck squamous cell carcinoma (HNSCC) [14]. In 2011 Visus et al. demonstrated that $\mathrm{ALDH}_{1 \mathrm{~A}} 1_{88-96}$ peptide-specific $\mathrm{CD} 8^{+} \mathrm{T}$ cells could recognise ALDH ${ }^{\text {bright }}$ cancer-initiating cells present in HLA-A2 ${ }^{+}$ human head and neck, breast and pancreas carcinoma cell lines, xenografts, or surgically removed lesions in vitro [15]. Moreover, in the human tumour xenograft model adoptive transfer of ALDH1-specific CD8 ${ }^{+} \mathrm{T}$ cells inhibited growth of subcutaneously growing tumours and lung metastases. Liao et al. reported that putative CSCS generated from two HNSCC cell lines and cervical carcinoma cell line CaSki were very sensitive to MHC class I-restricted alloantigen-specific CD8 ${ }^{+}$CTL lysis after treatment with IFN- $\gamma$ that up-regulated $\mathrm{MHC}$ I expression [16]. Also, the subset

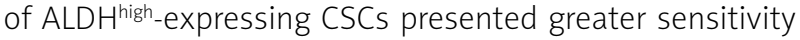
toward CD8+ CTL killing than the ALDH ${ }^{\text {low }}$ cells. Autologous tumour-infiltrating lymphocytes and autologous CTL clones derived from peripheral blood of patients were shown to specifically recognise and kill CSCs of malignant fibrous histiocytoma of the bone [17].

Ahmed et al. developed HER-2-specific T cells from glioblastoma multiforme (GBM) patients by genetic transfer of HER2-specific chimeric antigen receptor [18]. These HER2-specific $T$ cells showed cytotoxicity against HER2-positive targets in vitro and secreted immunostimulatory Th1 cytokines. The HER2-positive T cells killed in vitro autologous CD133-positive GBM stem cells, expressing HER2. These cells are resistant to current standard 
Table 1. Immunotherapeutic strategies that target cancer stem cells

\begin{tabular}{|c|c|c|c|c|}
\hline Therapeutic agent & Targets & Disease & Status & References \\
\hline \multicolumn{5}{|c|}{ Cancer vaccines } \\
\hline \multirow{8}{*}{ Dendritic cells } & $\mathrm{CSCS}$ & Glioblastoma & \multirow{3}{*}{ Preclinical (in vitro) } & $3,4,60$ \\
\hline & $\mathrm{CSCS} / \mathrm{ALDH}^{+}$ & $\begin{array}{c}\text { Melanoma, squamous cell } \\
\text { cancer }\end{array}$ & & 7 \\
\hline & $\begin{array}{l}\text { Vascular progenitor } \\
\text { antigens }\end{array}$ & Sarcoma & & 8 \\
\hline & Survivin, hTERT & Glioblastoma & Clinical trial, phase I, II & 9 \\
\hline & $\mathrm{CSCS}$ & Glioblastoma & \multirow{2}{*}{ Clinical trial, phase I } & 10 \\
\hline & CSCs/CD133+ & Glioblastoma & & 11 \\
\hline & $\mathrm{CSCS}$ & Melanoma & \multirow{2}{*}{ Clinical trial, phase II } & 61 \\
\hline & $\mathrm{CSCS} / \mathrm{HER} 2^{+}$ & Breast cancer & & 62 \\
\hline \multirow{7}{*}{ CTL } & CSCS & $\begin{array}{l}\text { Cervical cancer, head and neck } \\
\text { cancer }\end{array}$ & \multirow{7}{*}{ Preclinical (in vivo) } & 16 \\
\hline & $\mathrm{CSCS} / \mathrm{ALDH}^{+}$ & Malignant fibrous histiocytoma & & 17 \\
\hline & $\mathrm{CSCs} / \mathrm{CD} 44^{+} / \mathrm{CD} 24^{10}$ & Breast cancer & & 63 \\
\hline & CEPP-55 peptide & Colon cancer & & 64 \\
\hline & $\mathrm{CSCs} / \mathrm{ALDH}^{+}$ & Lung cancer & & 15 \\
\hline & $\mathrm{CSCS} / \mathrm{HER} 2^{+}$ & Glioblastoma multiforme & & 18 \\
\hline & $\begin{array}{l}\text { DNAJB8 heat shock } \\
\text { protein }\end{array}$ & Colorectal cancer & & 19 \\
\hline hiPSC/hESC & \multirow{4}{*}{ CSCs } & Colon cancer & \multirow{4}{*}{ Preclinical (in vivo) } & 22 \\
\hline mESC & & Lewis lung carcinoma & & 23 \\
\hline $\begin{array}{l}\text { mESC with GM-CSF } \\
\text { expressing fibroblasts }\end{array}$ & & Lung cancer & & 24 \\
\hline hESC with MWCNTs & & Colon cancer & & 58 \\
\hline PSCA cDNA mPSCA-VRP & CSCS-PSCA antigen & Prostate cancer & Preclinical (in vivo) & 59 \\
\hline NK cells & $\mathrm{CSCs} / \mathrm{CD}_{133^{+}}$ & Melanoma & Preclinical (in vitro) & 65 \\
\hline$\gamma \delta \top$ lymphocytes & $\mathrm{CSCS}$ & Ovarian cancer & Preclinical (in vivo) & 66 \\
\hline & & Monoclonal antibodies & & \\
\hline $\mathrm{H} 90$ & \multirow{7}{*}{ CD44 } & $\mathrm{AML}$ & \multirow{5}{*}{ Preclinical (in vivo) } & 67 \\
\hline P245 & & Breast cancer & & 28 \\
\hline $\mathrm{H} 4 \mathrm{C} 4$ & & Pancreatic cancer & & 68 \\
\hline GV5 & & Cervix cancer, larynx cancer & & 30 \\
\hline R05429083 & & HNSCC & & 31 \\
\hline RO5429083 & & $\begin{array}{l}\text { Metastatic/locally advanced, } \\
\text { CD44-expressing solid tumours }\end{array}$ & \multirow[t]{2}{*}{ Clinical trial, phase I } & 33 \\
\hline RO5429083 & & AML & & 34 \\
\hline \multirow[b]{2}{*}{ MT110 (Solitomab) } & \multirow[b]{2}{*}{ EpCAM } & $\begin{array}{l}\text { Ovarian cancer, colon cancer, } \\
\text { pancreatic cancer }\end{array}$ & Preclinical (in vivo) & 37,38 \\
\hline & & $\begin{array}{l}\text { Lung cancer, gastric cancer, } \\
\text { breast cancer, colorectal cancer, } \\
\text { prostate cancer, ovarian cancer }\end{array}$ & Clinical trial, phase I & 39,76 \\
\hline
\end{tabular}


Table 1. Cont.

\begin{tabular}{|c|c|c|c|c|}
\hline Therapeutic agent & Targets & Disease & Status & References \\
\hline \multirow{2}{*}{ Catumaxomab } & \multirow{2}{*}{ EpCAM/anti-CD3/Fc $\gamma$} & $\begin{array}{l}\text { Ovarian cancer, pancreatic } \\
\text { cancer, gastric cancer }\end{array}$ & Clinical trial, phase I-III & 40,41 \\
\hline & & Epithelial carcinoma & Clinical trial, phase I & 76 \\
\hline $\begin{array}{l}\text { Demcizumab } \\
\text { (OMP-21M18) }\end{array}$ & DLL4 & $\begin{array}{c}\text { Colon cancer, breast cancer, } \\
\text { melanoma }\end{array}$ & Preclinical (in vivo) & 51,52 \\
\hline \multirow[b]{2}{*}{ B6H12.2 } & \multirow{3}{*}{ CD47 } & $\begin{array}{l}\text { Glioblastoma, breast cancer, } \\
\text { bladder cancer, colon cancer }\end{array}$ & \multirow{3}{*}{ Preclinical (in vivo) } & 69 \\
\hline & & $\begin{array}{l}\text { Non-Hodgkin lymphoma, } \\
\text { acute lymphoblastic leukaemia, } \\
\text { multiple myeloma }\end{array}$ & & 70,71 \\
\hline $\mathrm{B} 6 \mathrm{H} 12$ & & $\begin{array}{l}\text { Aggressive metastatic } \\
\text { leiomyosarcoma }\end{array}$ & & 72 \\
\hline $7 \mathrm{G3}$ & \multirow{2}{*}{ CD123 } & \multirow{2}{*}{ AML } & Preclinical (in vivo) & 73 \\
\hline CSL360 & & & Clinical trial, phase I & 74 \\
\hline \multirow{2}{*}{ AVE1642 } & \multirow{5}{*}{ IGF-IR } & Myeloma, colon cancer & Preclinical (in vivo) & 87 \\
\hline & & Solid tumours & Clinical trial, phase I & 77 \\
\hline \multirow{3}{*}{$\begin{array}{l}\text { Figitumumab } \\
\text { (CP-751,871) }\end{array}$} & & Colon cancer & Preclinical (in vivo) & 78 \\
\hline & & Lung cancer, solid tumours & Clinical trial, phase I-III & $79-81$ \\
\hline & & $\begin{array}{l}\text { Solid tumours, colorectal cancer, } \\
\text { pancreatic cancer, lung cancer }\end{array}$ & Clinical trial, phase I & $82-85$ \\
\hline Bispecific antibody (BsAb) & EGFRvIIIț/CD133ț & Glioblastoma & Preclinical (in vivo) & 86 \\
\hline
\end{tabular}

therapies and may contribute to tumour recurrence in GBM. Adoptive transfer of HER2-specific T cells resulted in prolonged regression of autologous orthotropic GBM xenografts, confirming the potent antitumor activity of genetically modified $T$ cells against HER2-positive tumours and their putative stem cells.

Very recently Morita et al. [19] found that DNAJB8 heat shock protein was preferentially expressed in CSCs derived from colorectal cancer (CRC) rather than in non-CSCs. They identified immunogenic DNAJB8 peptides and induced DNAJB8-specific cytotoxic $T$ lymphocyte $(\mathrm{CTL})$ response. A CTL clone specific for DNAJB8 peptide showed higher killing activity to CRC CSCs compared with non-CSCS in vitro. The antitumor effect of the DNAJB8-specific CTL clone was evaluated in vivo using a therapeutic CTL adoptive transfer model. The DNAJB8-CTL clone-transferred group showed a significant antitumor effect compared with that in the control group.

\section{Pluripotent stem cells as cancer vaccines}

The antigenic similarities between malignant and embryonic cells are reflected by the expression of oncofoetal antigens by both cancer-initiating and pluripotent cells. It was reported in 1906 that prior injection of mice with foetal tissues led to rejection of transplantable tumours [20]. Such tumour protection was observed later for chemically induced cancers of skin, liver, and gastrointestinal tracts [21]. It can be concluded that animals or humans immunised against embryonic antigens might be capable of recognising and destroying neoplastic cells, which has been the premise for designing a novel immunotherapy approach. It has been shown that pluripotent ESCs induce modest delays in tumour growth in mouse models of transplantable colon and lung cancer $[22,23]$. Protection against CT26 colon carcinoma, generated by vaccination with hESC line $\mathrm{H} 9$, correlated with expansion of tumourresponsive IFN- $\gamma$-producing cells and loss of $\mathrm{CD}_{1} 1^{+} \mathrm{Gr} 1^{+}$ MDSCs in spleen [22]. Furthermore, administration of ESCS in lung carcinoma-bearing mice induced potent antitumor effect and protected mice from tumour growth [23]. Yaddanapudi et al. reported that vaccination with ESC in combination with GM-CSF was effective in preventing implantable and carcinogen-induced lung tumours, without detectable toxicity or autoimmunity. The therapeutic efficacy of this vaccine was associated with tumour-specific primary and long-term memory $\mathrm{CD}^{+}$effector responses, infiltration of $\mathrm{CD}^{+} \mathrm{T}$ cells into the tumour, and reduced MDCSs in the spleen [24]. These findings provide a strong rationale for further developing this form of immunotherapy, although it has to be kept in mind that the use of human embryonic cells for therapy purposes is highly controversial.

\section{Monoclonal antibodies}

Monoclonal antibodies used in immunotherapies posses the ability to activate the immune system against tumour cells, inhibit cancer cell-intrinsic signalling pathways, bring toxins to close proximity of cancer cells, or interfere with the tumour-stroma interaction. Several antibodies have been approved by the FDA for the treatment of solid 
and haematological tumours, e.g. rituximab (anti-CD20), cetuximab (anti-EGFR), trastuzumab (anti-HER2), bevacizumab (anti-VEGF-A), ipilimumab (anti-CTLA-4), and very recently pembrolizumab (anti-PD-1). The full potential of mAb is still to be exploited, and CSCs are currently increasingly important targets for antibody-based therapies.

CD44 is a transmembrane glycoprotein overexpressed in many tumour cells. It participates in the growth, survival, differentiation, and motility of cells, cell-adhesion, and the assembly of growth factors on the cell surface. Expression of CD44 is associated with metastasis, invasion, and aggressiveness of tumour growth [25]. CD44 is described as a marker of breast cancer stem cells and has been implicated as a CSC marker in bladder, gastric, prostate, pancreatic, ovarian, colorectal, hepatocellular, head, and neck squamous cell carcinomas [26]. Among CD44-based therapeutic strategies is the use of monoclonal antibodies. In vivo administration of anti-CD44 mAb to NOD-SCID mice transplanted with human acute myeloid leukemia (AML) led to efficient and selective eradication of AML leukaemic stem cells (LSC) [27]. Manipulation of CD44 function resulted in differentiation and inhibited proliferation, and engraftment and homing of CD34+CD38-LSCs from AML patients. Antibody-mediated CD44-targeting significantly reduced the growth of human breast cancer xenografts [28]. Moreover, mAb treatment during tumour remission induced by chemotherapy decreased tumour recurrence to $31 \%$ in mice injected with human triple-negative basal-like breast cancer cells. In mice with human pancreatic tumour xenografts anti-CD44 mAb reduced growth, metastasis, and post-radiation recurrence [29]. The antibody decreased the number of CSCs in both cultured pancreatic cancer cells and in xenograft tumours, as well as their tumourigenicity. Monoclonal antibody targeting CD44R1, an alternative splice variant of CD44 that is overexpressed in colon, bladder, lung, larynx and breast cancer, inhibited tumour growth of human cervix and larynx carcinoma xenografts [30]. In head and neck squamous cell carcinoma, treatment with anti-CD44 mAb displayed remarkable tumour growth inhibition, accompanied by the inhibition of constitutive EGFR phosphorylation on HNSCC cell line xenografts [31]. This phosphorylation has been associated with early relapse and poor prognosis in HNSCC patients [32]. Encouraging preclinical results have led anti-CD44 mAbs to clinical trials. RO5429083 has been tested alone and in combination with cytarabine in patients with $A M L$ or metastatic CD44-expressing malignant solid tumours [33, 34].

The epithelial cell adhesion molecule (EpCAM, CD326) is a transmembrane glycoprotein, overexpressed in most human carcinomas, which has been identified as an additional marker for cancer-initiating stem cells [35]. The EpCAM overexpression has been utilised in several EpCAM directed antibody-based preclinical studies and clinical trials [36]. Solitomab (MT110) is a single-chain bispecific T-cell engager (BiTE) antibody targeting EpCAM [37]. It prevented the outgrowth of SW480 human colon cancer xenografts and led to durable eradication of established tumours. Treatment with MT110 also resulted in remission of subcutaneous human ovarian cancer xenografts. Cioffi et al. reported elimination of tumour-initiating cells from
MT110 in vitro-treated primary human pancreatic cells [38]. In vivo studies using a mouse model of established primary human pancreatic cancer revealed disease stabilisation in response to MT110. Small remaining tumours were depleted of CSCs and contained mostly differentiated cancer cells. Since 2008 MT110 has been tested in dose escalation phase I clinical trials in patients with locally advanced, recurrent or metastatic lung, gastric, colorectal, breast, hormone-refractory prostate, and ovarian cancers. Anti-tumour response was evaluated in sixteen patients who received a dose of $\geq 24 \mu \mathrm{g} / \mathrm{d}$ [39]. In $38 \%$ of patients, disease stabilisation was observed with median duration of 155 days, and anti-tumour activity was demonstrated in a biopsy of liver metastases in one patient. Catumaxomab is a bispecific, trifunctional antibody that effectively binds to EpCAM antigen on tumour/CSC cells and to CD3 co-receptor on $T$ lymphocytes. In addition, catumaxomab attaches to and activates FcyRI/IIa/III-expressing macrophages, DCs, and NK cells via its specific Fc region [40]. That makes catumaxomab a self-supporting system, without the need for additional immune system activation. Catumaxomab effectively eliminated CD133+/EpCAM ${ }^{+}$CSCs from patients with severe ovarian, pancreatic, and gastric cancers [41]. Moreover, catumaxomab is in phase I-III of clinical trials for epithelial cancers. It is commercially available on the European Union market for therapy of malignant ascites caused by epithelial cancers [40].

CD133 (prominin-1) was first identified as a CD34+ haematopoietic stem cell marker [42]. Cancer stem cells expressing CD133 were subsequently reported in brain, coIon, prostate, lung, ovarian, pancreatic, and hepatocellular carcinomas [43]. In order to eradicate CD133 ${ }^{\text {high }}$ cancer cells, Huang et al. generated a bispecific antibody (BsAb) against CD3 and CD133 [44]. They combined antibody therapy with cellular immunotherapy by arming cytokine-induced killer (CIK) cells with the novel BsAb to create BsAb-CIKs. The BsAb-CIK cells killed CD133 $3^{\text {high }}$ pancreatic and hepatic cancer cells in vitro more efficiently than the parental CIK or CIK cells bound with anti-CD3 (CD3-CIK) without CD133 targeting and produced significantly higher amounts of IFN- $\gamma$. In nude mice, the BsAb-CIK cells significantly inhibited CD133 high tumour growth by selectively targeting this cell population.

Notch signalling modulates differentiation, survival, proliferation, and apoptosis of CSCs [45, 46]. Aberrant Notch signalling is responsible for promotion of tumorigenesis, multiresistance, and self-renewal of CSCs [46]. Delta-like ligand (DLL) is one of the canonical ligands in Notch signalling [47]. Overexpression of DLL in tumour cells led to activation of Notch signalling and cancer progression, while blockade of DLL resulted in poor tumour perfusion, hypoxia, and tumour shrinking [48-50]. Blockade of DLL with monoclonal anti-human antibody in human colon tumour xenograft produced a decrease in tumour growth that correlated with a 50\% decrease in the CSC population [51]. Beviglia et al. reported a significant inhibition of both primary tumour and metastases in the lungs, liver, intestine, and brain in a xenograft mice human melanoma model after treatment with anti-DLL4 $\mathrm{mAb}$ [52]. Yen et al. found that treatment with anti-DLL4 
antibody decreased CSC frequency in residual tumours after conventional chemotherapy in patient-derived breast cancer and pancreatic cancer xenografts [53]. That led to growth inhibition of resistant tumours and re-sensitised them to the chemotherapeutic agent. With a rationale from pre-clinical studies to target CSCs through interference with Notch pathway anti-DLL4 mAb went to clinical trials. Demcizumab (OMP-21M18) is currently being tested in combination with chemotherapy in several phase $\mathrm{I} / \mathrm{lb}$ trials, in advanced or metastatic solid tumours [54-56]. In February 2014 the safety and tolerability phase I study of REGN421 (SAR153192), a fully humanised mAb against DLL4, in patients with advanced solid malignancies, was completed. Although full results have not been published yet, preliminary data show an acceptable safety profile of REGN421 and anti-tumour activity, which include 2 partial responses and 16 patients with stable disease [55].

\section{Conclusions}

As shown above, numerous in vitro and in vivo studies or clinical trials indicate that immune targeting of CSCS presents a promising approach for cancer treatment. The major advantages of most immunotherapeutic strategies are low or acceptable toxicity and the ability to target defined molecules or cell populations. On the other hand, immunotherapy is more effective in some types of cancer and often needs to be accompanied by traditional treatment strategies such as chemotherapy. Nevertheless, it is becoming a fascinating tool in the fight against cancer, and its further development in the near future is guaranteed.

The authors declare no conflict of interest.

This work was supported by the National Science Centre grant 2012/07/B/NZ6/03495 and National Centre for Research and Development grant INNOMED/I/6/NCBR/2014.

\section{References}

1. Moncharmont C, Levy A, Gilormini M, et al. Targeting a cornerstone of radiation resistance: cancer stem cell. Cancer Lett 2012; 322: 139-47.

2. Palucka K. Q\&A: Evidence presenter. Interview by Marian Turner. Nature 2013; 504: S9.

3. Pellegatta S, Poliani PL, Corno D, et al. Neurospheres enriched in cancer stem-like cells are highly effective in eliciting a dendritic cell-mediated immune response against malignant gliomas. Cancer Res 2006; 66: 10247-52.

4. Xu Q, Liu G, Yuan X, et al. Antigen-specific T-cell response from dendritic cell vaccination using cancer stem-like cell-associated antigens. Stem Cells 2009; 27: 1734-40.

5. Kim MP, Fleming JB, Wang $H$, et al. ALDH activity selectively defines an enhanced tumor-initiating cell population relative to CD133 expression in human pancreatic adenocarcinoma. PLoS One 2011; 6: e20636.

6. Ma S, Chan KW, Lee TK, Tang KH, Wo JY, Zheng BJ, Guan XY. Aldehyde dehydrogenase discriminates the CD133 liver cancer stem cell populations. Mol Cancer Res 2008; 6: 1146-53.

7. Ning N, Pan Q, Zheng F, et al. Cancer stem cell vaccination confers significant antitumor immunity. Cancer Res 2012; 72: 1853-64.

8. Koido S, Ito M, Sagawa Y. Vaccination with vascular progenitor cells derived from induced pluripotent stem cells elicits antitumor immunity targeting vascular and tumor cells. Cancer Immunol Immunother 2014; 63: 459-68.

9. Vik-Mo EO, Nyakas M, Mikkelsen BV, et al. Therapeutic vaccination against autologous cancer stem cells with mRNA-transfected dendritic cells in patients with glioblastoma. Cancer Immunol Immunother 2013; 62: 1499-509.

10. Phase I Study of a Dendritic Cell Vaccine for Patients With Either Newly Diagnosed or Recurrent Glioblastoma. ClinicalTrials.gov; available at: http://clinicaltrials.gov/show/NCT02010606

11. A Study of ICT-121 Dendritic Cell Vaccine in Recurrent Glioblastoma. ClinicalTrials.gov; available at: http://clinicaltrials.gov/show/ NCT02049489

12. Kershaw MH, Westwood JA, Darcy PK. Gene-engineered T cells for cancer therapy. Nat Rev Cancer 2013; 13: 525-41.

13. Restifo NP, Dudley ME, Rosenberg SA. Adoptive immunotherapy for cancer: harnessing the T cell response. Nat Rev Immunol 2012; 12: 269-81.

14. Visus C, Ito D, Amoscato A. Identification of human aldehyde dehydrogenase 1 family member A1 as a novel CD8+ T-cell-defined tumor antigen in squamous cell carcinoma of the head and neck. Cancer Res 2007; 67: 10538-45.

15. Visus C, Wang Y, Lozano-Leon A, et al. Targeting ALDH(bright) human carcinoma initiating cells with ALDH1A1- specific CD8+ T cells. Clin Cancer Res 2011; 17: 6174-84.

16. Liao T, Kaufmann AM, Qian X, Sangvatanakul V, Chen C, Kube T, Zhang G, Albers AE. Susceptibility to cytotoxic T cell lysis of cancer stem cells derived from cervical and head and neck tumor cell lines. J Cancer Res Clin Oncol 2013; 139: 159-70.

17. Kano M, Tsukahara T, Emori M, et al. Autologous CTL response against cancer stem-like cells/cancer-initiating cells of bone malignant fibrous histiocytoma. Cancer Sci 2011; 102: 1443-7.

18. Ahmed N, Salsman VS, Kew Y, et al. HER2-specific t cells target primary glioblastoma stem cells and induce regression of autologous experimental tumors. Clin Cancer Res 2010; 16: 474-85.

19. Morita R, Nishizawa S, Torigoe T, et al. Heat shock protein DNAJB8 is a novel target for immunotherapy of colon cancer-initiating cells. Cancer Sci 2014; 105: 389-95.

20. Schöne G. Untersuchungen über Karzinomimmunität bei Mäusen. Münch Med Wochenschr 1906; 51: 2517-9.

21. Brewer BG, Mitchell RA, Harandi A, Eaton JW. Embryonic vaccines against cancer: an early history. Exp Mol Pathol 2009; 86: 192-7.

22. Li Y, Zeng H, Xu RH, Liu B, Li Z. Vaccination with human pluripotent stem cells generates a broad spectrum of immunological and clinical responses against colon cancer. Stem Cells 2009; 27: 3103-11.

23. Dong W, Du J, Shen H, Gao D, Li Z, Wang G, Mu X, Liu Q. Administration of embryonic stem cells generates effective antitumor immunity in mice with minor and heavy tumor load. Cancer Immunol Immunother 2010; 59: 1697-705.

24. Yaddanapudi K, Mitchell RA, Putty K, Willer S, Sharma RK, Yan J, Bodduluri H, Eaton JW. Vaccination with Embryonic Stem Cells Protects against Lung Cancer: Is a Broad-Spectrum Prophylactic Vaccine against Cancer Possible? PLoS ONE 2012; 7: e42289.

25. Negi LM, Talegaonkar S, Jaggi M, Ahmad FJ, Iqbal Z, Khar RK. Role of CD44 in tumour progression and strategies for targeting. J Drug Target 2012; 20: 561-73.

26. Du L, Wang H, He L, et al. CD44 is of functional importance for colorectal cancer stem cells. Clin Cancer Res 2008; 14: 6751-60.

27. Jin L, Hope KJ, Zhai Q, Smadja-Joffe F, Dick JE. Targeting of CD44 eradicates human acute myeloid leukemic stem cells. Nat Med 2006; 12: 1167-74.

28. Marangoni E, Lecomte N, Durand L, de Pinieux D, Decaudin D, Chomienne C, Smadja-Joffe F, Poupon M-F. CD44 targeting reduces tumour growth and prevents post-chemotherapy relapse of human breast cancers xenografts. Br J Cancer 2009; 100: 918-22.

29. Li L, Hao X, Qin J, et al. Antibody against CD44s inhibits pancreatic tumor initiation and postradiation recurrence in mice. Gastroenterology 2014; 146: 1108-18.

30. Masuko K, Okazaki S, Satoh M, et al. Anti-tumor effect against human cancer xenografts by a fully human monoclonal antibody to a variant 8-epitope of CD44R1 expressed on cancer stem cells. PLoS One 2012; 7: e29728. 
31. Perez A, Neskey DM, Wen J, Goodwin JW, Slingerland J, Pereira Weigand S, Franzmann EJ. Abstract 2521: Targeting CD44 in head and neck squamous cell carcinoma (HNSCC) with a new humanized antibody RO5429083. In: Proceedings: AACR 103rd Annua Meeting 2012 - Mar 31-Apr 4, 2012; Chicago, IL. Cancer Res 2012; 72 (8 Suppl 1).

32. Hama T, Yuza Y, Saito Y, et al. Prognostic significance of epidermal growth factor receptor phosphorylation and mutation in head and neck squamous cell carcinoma. Oncologist 2009; 14: 900-8.

33. A study of R05429083 in patients with metastatic and/or locally advanced, CD44-expressing, malignant solid tumors. ClinicalTri als.gov; available at: http://clinicaltrials.gov/show/NCT01358903

34. A study of RO5429083 alone or in combination with cytarabine in patients with acute myelogenous leukemia. ClinicalTrials.gov; available at: http://clinicaltrials.gov/show/NCT01641250

35. Van der Gun BT, Melchers LJ, Ruiters MH, de Leij LF, McLaughlin PM, Rots MG. EpCAM in carcinogenesis: the good, the bad or the ugly. Carcinogenesis 2010; 31: 1913-21.

36. Baeuerle PA, Gires O. EpCAM (CD326) finding its role in cancer Br J Cancer 2007; 96: 417-23.

37. Brischwein K, Schlereth B, Guller B, et al. MT110: a novel bispecific single-chain antibody construct with high efficacy in eradicating established tumors. Mol Immunol 2006; 43: 1129-43.

38. Cioffi M, Dorado J, Baeuerle PA, Heeschen C. EpCAM/CD3-Bispecific T-cell engaging antibody MT110 eliminates primary human pancreatic cancer stem cells. Clin Cancer Res 2012; 18: 465-74.

39. Fiedler WM, Wolf M, Kebenko M, et al. A phase I study of EpCAM CD3-bispecific antibody (MT110) in patients with advanced solid tumors. J Clin Oncol 2012; 30 (suppl; abstr 2504).

40. Seimetz D. Novel monoclonal antibodies for cancer treatment: the trifunctional antibody catumaxomab (removab). J Cancer 2011; 2: 309-16.

41. Jäger $M$, Schoberth $A$, Ruf $P$, et al. Immunomonitoring results of a phase II/III study of malignant ascites patients treated with the trifunctional antibody catumaxomab (anti-EpCAM $x$ anti-CD3). Cancer Res 2012; 72: 24-32.

42. Yin AH, Miraglia S, Zanjani ED, et al. AC133, a novel marker for human hematopoietic stem and progenitor cells. Blood 1997; 90: 5002-12.

43. Grosse-Gehling P, Fargeas CA, Dittfeld C, Garbe Y, Alison MR, Corbeil D, Kunz-Schughart LA. CD133 as a biomarker for putative can cer stem cells in solid tumours: limitations, problems and challenges. J Pathol 2013; 229: 355-78.

44. Huang J, Li C, Wang Y, LV H, Guo Y, Dai H, Wicha MS, Chang AE, Li O. Cytokine-induced killer (CIK) cells bound with anti-CD3/anti-CD133 bispecific antibodies target CD133high cancer stem cells in vitro and in vivo. Clin Immunol 2013; 149: 156-68.

45. Bridges E1, Oon CE, Harris A. Notch regulation of tumor angiogenesis. Future Oncol 2011; 7: 569-88.

46. Wang Z, Li Y, Banerjee S, Sarka FH. Emerging role of Notch in stem cells and cancer. Cancer Lett 2009; 279: 8-12.

47. Chillakuri CR, Sheppard D, Lea SM, Handford PA. Notch receptor-ligand binding and activation: insights from molecular studies. Semin Cell Dev Biol 2012; 23: 421-8.

48. Patel NS, Li JL, Generali D, Poulsom R, Cranston DW, Harris AL. Upregulation of delta-like 4 ligand in human tumor vasculature and the role of basal expression in endothelial cell function. Cancer Res 2005; 65: 8690-7.

49. Noguera-Troise I, Daly C, Papadopoulos NJ, et al. Blockade of DII4 inhibits tumour growth by promoting non-productive angiogenesis. Nature 2006; 444: 1032-7.

50. Kuhnert F, Kirshner JR, Thurston G. DII4-Notch signaling as a therapeutic target in tumor angiogenesis. Vasc Cell 2011; 3: 20.

51. Hoey T, Yen WC, Axelrod F, et al. DLL4 blockade inhibits tumor growth and reduces tumor-initiating cell frequency. Cell Stem Cell 2009; 5: 168-77.

52. Beviglia L, Yeung P, Fischer M, Yen WC, Lewicki J, Gurney A, Hoey TM, Kapoun A. Abstract 2834: Anti-DLL4 treatment inhibits melanoma tumor growth, recurrence, metastases, and reduces frequency of cancer stem cells in a clinically relevant tumor mode in NOD/SCID mice. In: Proceedings: AACR 102nd Annual Meeting 2011 - Apr 2-6, 2011; Orlando, FL. Cancer Res 2011; 71 (8 Suppl 1).
53. Yen WC, Fischer M, Lewicki J, Gurney A, Hoey TM. Abstract 3357 : Targeting cancer stem cells by an anti-DLL4 antibody inhibits epithelial-to-mesenchymal transition, delays tumor recurrence and overcomes drug resistance in breast and pancreatic cancer. In: Proceedings: AACR 103rd Annual Meeting 2012 - Mar 31-Apr 4 2012; Chicago, IL. Cancer Res 2012; 72 (8 Suppl 1).

54. A Study of Carboplatin and Pemetrexed Plus Demcizumab (OMP 21M18) in Subjects With Non-Squamous Non-Small Cell Lung Cancer. ClinicalTrials.gov; available at: http://clinicaltrials.gov/ show/NCT01189968

55. A Study of Gemcitabine and Demcizumab (OMP-21M18) With or Without Abraxane ${ }^{\circledR}$ as 1st-line Treatment in Subjects With Locally Advanced or Metastatic Pancreatic Cancer. ClinicalTrials.gov; available at: http://clinicaltrials.gov/show/NCT01189929

56. A Study of Demcizumab Plus Paclitaxel in Subjects With Platinum Resistant Ovarian (SIERRA). ClinicalTrials.gov; available at: http:// clinicaltrials.gov/show/NCT01952249

57. Jimeno A, LoRusso P, Strother RM, et al. Phase I study of REGN421 (R)/SAR153192, a fully-human delta-like ligand 4 (DIl4) monoclonal antibody (mAb), in patients with advanced solid tumors. J Clin Oncol 2013; 31 (suppl; abstr 2502).

58. Mocan T, lancu C. Effective colon cancer prophylaxis in mice using embryonic stem cells and carbon nanotubes. Int J Nanomedicine 2011; 6: 1945-54.

59. Garcia-Hernandez Mde L, Gray A, Hubby B, Klinger OJ, Kast WM Prostate stem cell antigen vaccination induces a long-term protective immune response against prostate cancer in the absence of autoimmunity. Cancer Res 2008; 68: 861-9.

60. Baowei J, Qianxue C, Baohui L, Liquan W, Daofeng T, Zhentao G, Wei Y. Glioma Stem Cell-Targeted Dendritic Cells as a Tumor Vac cine Against Malignant Glioma. Yonsei Med J 2013; 54: 92-100.

61. Dillman RO, Cornforth AN, Depriest C, et al. Tumor stem cell antigens as consolidative active specific immunotherapy: a randomized phase II trial of dendritic cells versus tumor cells in patients with metastatic melanoma. J Immunother 2012; 35: 641-9.

62. Sharma A, Koldovsky U, Xu S, et al. HER-2 pulsed dendritic cell vaccine can eliminate HER-2 expression and impact ductal carcinoma in situ. Cancer 2012; 118: 4354-62.

63. Mine T, Matsueda S, Li Y, et al. Breast cancer cells expressing stem cell markers CD44+ CD24 lo are eliminated by Numb-1 peptide-activated T cells. Cancer Immunol Immunother 2009; 58: 1185-94.

64. Inoda S, Hirohashi Y, Torigoe T, et al. Cytotoxic T lymphocytes efficiently recognize human colon cancer stem-like cells. Am J Pathol 2011; 178: 1805-13

65. Pietra G, Manzini C, Vitale M, et al. Natural killer cells kill human melanoma cells with characteristics of cancer stem cells. Int Immunol 2009; 21: 793-801.

66. Lai D, Wang F, Chen Y, Wang C, Liu S, Lu B, Ge X, Guo L. Human ovarian cancer stem-like cells can be efficiently killed by $\gamma \delta$ T lymphocytes. Cancer Immunol Immunother 2012; 61: 979-89.

67. Charrad RS, Li Y, Delpech B, Balitrand N, Clay D, Jasmin C, Chomienne C, Smadja-Joffe F. Ligation of the CD44 adhesion molecule reverses blockage of differentiation in human acute myeloid leu kemia. Nat Med 1999; 5: 669-76.

68. Tang W, Hao X, He F, Li L, Xu L. Abstract 565: Anti-CD44 antibody treatment inhibits pancreatic cancer metastasis and post-radiotherapy recurrence. Proceedings: AACR 102nd Annual Meeting 2011 - Apr 2-6 2011; Orlando, FL. Cancer Res 2011; 71 (8 Suppl 1).

69. Willingham SB, Volkmer JP, Gentles AJ, et al. The CD47-signal regulatory protein alpha (SIRPa) interaction is a therapeutic target for human solid tumors. Proc Natl Acad Sci USA 2012; 109: 6662-67.

70. Chao MP, Tang C, Pachynski RK, Chin R, Majeti R, Weissman IL. Extranodal dissemination of non-Hodgkin lymphoma requires CD47 and is inhibited by anti-CD47 antibody therapy. Blood 2011; 118: 4890-901.

71. Chao MP, Alizadeh AA, Tang C, et al. Therapeutic antibody targeting of CD47 eliminates human acute lymphoblastic leukemia. Cancer Res 2011; 71: 1374-84.

72. Edris B, Weiskopf K, Volkmer AK, et al. Antibody therapy targeting the CD47 protein is effective in a model of aggressive metastatic leiomyosarcoma. Proc Natl Acad Sci USA 2012; 109: 6656-61. 
73. Jin L, Lee EM, Ramshaw HS, et al. Monoclonal antibody-mediated targeting of CD123, IL-3 receptor a chain, eliminates human acute myeloid leukemic stem cells. Cell Stem Cell 2009; 5: 31-42.

74. Roberts AW, He S, Ritchie D, et al. A phase I study of anti-CD123 monoclonal antibody (mAb) CSL360 targeting leukemia stem cells (LSC) in AML. J Clin Oncol 2010; 28 (suppl; abstr e13012).

75. Phase I Study of MT110 in Lung Cancer (Adenocarcinoma and Small Cell), Gastric Cancer or Adenocarcinoma of the Gastro-Esophageal Junction, Colorectal Cancer, Breast Cancer, Hormone-Refractory Prostate Cancer, and Ovarian Cancer (MT110101). ClinicalTrials.gov; available at: http://clinicaltrials.gov/show/ NCT00635596

76. A Open Label, Dose Escalating Study to Evaluate the Safety and Tolerability of Ascending Intravenous (i.v.) Doses of Catumaxomab in Epithelial Cancer Patients. ClinicalTrials.gov; available at: http://clinicaltrials.gov/show/NCT01320020

77. Macaulay VM, Middleton MR, Protheroe AS, et al. Phase I study of humanized monoclonal antibody AVE1642 directed against the type 1 insulin-like growth factor receptor (IGF-1R), administered in combination with anticancer therapies to patients with advanced solid tumors. Ann Oncol 2013; 24: 784-91.

78. Hart LS, Dolloff NG, Dicker DT, Constantinos Koumenis C, Christensen JG, Grimberg A, El-Deiry WS. Human colon cancer stem cells are enriched by insulin-like growth factor-1 and are sensitive to figitumumab. Cell Cycle 2011; 10: 2331-8.

79. Figitumumab Combined With Pegvisomant For Advanced Solid Tumors. ClinicalTrials.gov; available at: http://clinicaltrials.gov/ show/NCT00976508

80. A Study Of Cisplatin (Or Carboplatin) And Etoposide With Or Without Figitumumab (CP-751,871) In Patients With Extensive-Stage Small Cell Lung Cancer. ClinicalTrial.gov; available at: http://clinicaltrials.gov/show/NCT00977561

81. Trial Of CP-751, 871 And Erlotinib In Refractory Lung Cancer (NS CLC). ClinicalTrials.gov; available at: http://clinicaltrials.gov/ show/NCT00673049

82. A phase 1 dose escalation study of OMP-21M18 in subjects with solid tumors. ClinicalTrials.gov; available at: http://clinicaltrials. gov/show/NCT00744562

83. A phase $1 \mathrm{~b}$ study of FOLFIRI plus OMP-12M18 as 1 st or 2 nd line treatment in subjects with metastatic colorectal cancer. ClinicalTrials.gov; available at: http://clinicaltrials.gov/show/ NCT01189942

84. A phase $1 \mathrm{~b}$ study of gemcitabine plus OMP-21M18 as 1 st-line treatment in subjects with locally advanced or metastatic pancreatic cancer. ClinicalTrials.gov; available at: http://clinicaltrials. gov/show/NCT01189929

85. A phase $1 \mathrm{~b}$ study of carboplatin and pemetrexed plus OMP-21M18 as 1stline treatment in subjects with non-squamous non-small cell lung cancer. ClinicalTrials.gov; available at: http://clinicaltrials. gov/show/NCT01189968

86. Emlet DR, Gupta P, Holgado-Madruga M, et al. Targeting a glioblastoma cancer stem-cell population defined by EGF receptor variant III. Cancer Res 2014; 74: 1238-49.

87. Dallas NA, Xia L, Fan F, et al. Chemoresistant colorectal cancer cells, the cancer stem cell phenotype, and increased sensitivity to insulin-like growth factor-I receptor inhibition. Cancer Res 2009; 69: 1951-7.

\section{Address for correspondence}

\section{Eliza P. Kwiatkowska-Borowczyk}

Department of Cancer Immunology

University of Medical Sciences

Garbary 15

60-866 Poznan, Poland

e-mail: eliza.kwiatkowska@wco.pl 